6048

Research Article

Journal of Extension Education

Vol. 30 No. 2, 2018

DOI:https://doi.org/10.26725/JEE.2018.2.30.6048-6055

\title{
A study on Extent of Participation and Perception of Farmers on Benefits of IWMP (Integrated Watershed Management Programme)
}

\author{
Vaithiyanath ${ }^{1}$, G. Samuel ${ }^{2}$ and I. Sreenivasa Rao ${ }^{3}$
}

\begin{abstract}
Watershed is a basin-like landform defined by highpoints and ridgelines that descend into lower elevations and stream valleys. Watershed development involves conservation, regeneration and judicious utilization of natural resources. It aims to bring about an optimum balance between the demand and use of natural resources so that they remain sustainable over time. Ex-post-facto research design was adopted for the study with the objective to find out the extent of participation of watershed farmers in Integrated Watershed Management Programme (IWMP) and to find out its benefits. Majority of the watershed farmers had medium level of participation in IWMP followed by low and high participation. The independent variables viz., age, education, farming experience, training received, socio-political participation, efficiency of group leadership, group cohesiveness, decision making pattern and hard work oriented-ness were found positively and significantly related with the extent of participation of watershed farmers in IWMP.
\end{abstract}

Keywords: Watershed, Integrated Watershed Management Programme; Participation; Telangana

\section{INTRODUCTION}

Watershed is a basin-like landform defined by highpoints and ridgelines that descend into lower elevations and stream valleys. Watershed development involves conservation, regeneration and judicious utilization of natural resources. It aims to bring about an optimum balance between the demand and use of natural resources so that they remain sustainable over time. Bhattacharya (2008) gave a new definition to watershed as "It is to harmonize the water, soil, forest and pasture in a way that conserves these resources while raising agricultural production both by conserving the moisture in the soil and by increasing irrigation through tank and aquifer based water harvesting".

For implementation of IWMP watersheds, State Level Nodal Agency (SLNA) has been constituted by the State Government, the Principal Secretary of the Rural Development being the Chairperson and the Commissioner, Rural Development Department is the full-time CEO of the SLNA having an independent bank account. The District Water Management Agency (DWMA) implements these watersheds through Project Officers in 75 per cent of

1. Agriculture Officer, 2 \& 3 Professors, Dept. of Agricultural Extension, College of Agriculture, PJTSAU, Rajendra Nagar, Hyderabad, Telangana

Received : 06-01-2018; Accepted : 22-11-2018 
A study on extent of participation and perception of farmers on benefits of IWMP (Integrated Watershed Management Programme)

the sanctioned projects and 25 per cent of the projects through line departments, autonomous organizations under State/ Central Governments, Government Institutes / Research bodies, Intermediate Panchayats, Voluntary Organisations (VOs) by the Village Watershed Committees.

There is a close relationship between the environment and human community living within, for its livelihood. When the economic condition of a community deteriorates, it leads to over-exploitation and degradation of natural resources. It is necessary for the people to understand the relationship between their poverty and the degraded environment they live in. Environmental regeneration is possible only when the concerned people realize a need for it and empowered to have control over the process of resource utilization, management and conservation. As human beings their activities are the primary cause of environmental degradation, they can restore the health of the environment they have ruined by resetting their ways and activities towards the environment around. Hence, there can be no sustainable natural resource management unless it involves the participation of all inhabitants of the concerned environment in an active mode. Keeping this in mind, efforts were taken to find out the extent of participation of watershed farmers in Integrated Watershed Management Programme and to find out the benefits of Integrated Watershed Management Programme.

\section{METHODOLOGY}

The state of Telangana in India, was selected purposively for the study as the researcher hails from the state and is familiar with the regional language and cultural patterns.

Telangana state, comprising 10 districts namely Hyderabad, Rangareddy, Mahaboobnagar, Nalgonda, Nizamabad, Karimnagar, Adilabad, Medak, Warangal and Khammam is divided into three agro climatic zones viz., Southern Telangana, Northern Telangana and Central Telangana. Among the three agro climatic zones the Southern Telangana zone receives comparatively less rainfall than the other two. Among the districts of southern Telangana, Medak district consists of significant area under dryland agriculture and large number of IWMPs are being implemented in thes district. This district in Telangana state was selected purposively for the study. Out of total forty six (46) mandals in the district two mandals namely Sadashivpet and Kondapur were selected randomly for the study. From the two selected mandals three villages each namely Atmakur, Bobiligum and Yellaram from Sadashivpet and Mallepally, Terpole and Guntapally from Kondapur mandals were selected at random. A total of twenty (20) watershed farmers from each village were selected randomly making a total sample of 120 respondents.

Socio political participation was operationally defined as the degree of involvement of watershed farmer in social and political organizations prevailing in the village such as Village panchayat, Youth club, Water User's Association (WUA), Self Help Group (SHG), User Group (UG) and Village Watershed Development Committee (VWDC). 
Scoring: The individual total score was obtained by summing up all the scores of different organizations. The maximum and minimum possible scores were 21 and 6 respectively. The maximum and minimum scores obtained were 20 and 6 respectively.

\section{FINDINGS AND DISCUSSION}

\section{Extent of participation in IWMP}

The results indicate that majority of the farmers (54.20\%) had medium level of participation, followed by low (24.10\%), and high (21.70\%) participation in IWMP.

The medium level participation of farmers in IWMP might be due to the fact that majority of the farmers were small farmers and possess low level of education. Due to their low education level they do not depend on reading newspapers, farm magazines and agricultural news articles, thus there could be medium information seeking behavior which results in redium level of participated. The government need to take measures to inculcate team spirit in forming the groups among the watershed farmers to follow the community approach for participation in IWMP. Measures may also be taken up to conduct more awareness programmes on highlighting the importance of water harvesting structures. The State Department of Agriculture, DWMA and KVKs should conduct more awareness programmes, campaigns, exposure visits to inculcate the spirit of sensing the importance of water harvesting structures in watershed programme.

Saikat and Surya (2015) and Singh et al. (2010) also found similar results whereas Meshesha et al. (2015) found poor community participation in watershed management.

\section{Relationship between Profile characteristics and Extent of participation}

Null hypothesis: There will be no significant relationship between profile characteristics of watershed farmers and their extent of participation of IWMP.

Empirical hypothesis: There will be a significant relationship between profile characteristics of watershed farmers and their extent of participation of IWMP.

Table 1.

Correlation coefficient values between Profile characteristics and Dependent variables

$n=120$

\begin{tabular}{|c|l|c|}
\hline SI. No & \multicolumn{1}{|c|}{ Variables } & Participation \\
\hline 1 & Age & $0.1782^{*}$ \\
\hline 2 & Education & $0.1564^{*}$ \\
\hline 3 & Farm size & $0.1232 \mathrm{NS}$ \\
\hline 4 & Farming experience & $0.2434^{* *}$ \\
\hline 5 & Training received & $0.2583^{* *}$ \\
\hline 6 & Socio-political participation & $0.2660^{* *}$ \\
\hline 7 & Efficiency of group leadership & $0.1685^{*}$ \\
\hline
\end{tabular}


A study on extent of participation and perception of farmers on benefits of IWMP (Integrated Watershed Management Programme)

\begin{tabular}{|c|l|c|}
\hline SI. No & \multicolumn{1}{|c|}{ Variables } & Participation \\
\hline 8 & Group cohesiveness & $0.1443^{*}$ \\
\hline 9 & Decision making pattern & $0.1590^{*}$ \\
\hline 10 & Information seeking behaviour & $0.0726 \mathrm{NS}$ \\
\hline 11 & Annual income & $0.0629 \mathrm{NS}$ \\
\hline 12 & Hard work-orientedness & $0.1497^{*}$ \\
\hline 13 & Type of irrigation & $0.0678 \mathrm{NS}$ \\
\hline 14 & Enterprise possessed & $0.0719 \mathrm{NS}$ \\
\hline 15 & Net returns & $0.0730 \mathrm{NS}$ \\
\hline
\end{tabular}

${ }^{*}$ Significant at $5 \%$ level of probability; ${ }^{* *}$ Significant at $1 \%$ level of probability: NS- Non-significant

It is clearly evident from Table 1 that, the calculated ' $r$ ' values between participation and farming experience, training received and socio-political participation were greater than ' $r$ ' table value at 1.00 per cent level of probability which indicated positive and highly significant relationship. Age, education, efficiency of group leadership, group cohesiveness, decision making pattern and hard work orientedness were also positively and significantly correlated to participation at 5.00 per cent level of probability. Hence, null hypothesis was rejected and empirical hypothesis was accepted for the variables. Therefore, it can be concluded that there was a positive and significant relationship between the selected profile characteristics and extent of participation in IWMP.

On the other hand, the calculated ' $r$ ' values between participation and farm size, information seeking behaviour, annual income, type of irrigation, enterprise possessed and net returns were less than ' $r$ ' table value. Hence null hypothesis is accepted and empirical hypothesis was rejected for these variables. Therefore, it can be concluded that there was no significant relationship between these profile characteristics and extent of participation in IWMP.

It is also observed from Table 2 that, the calculated ' $r$ ' values between perception and training received and decision making pattern were greater than table ' $r$ ' value at 1.00 per cent level of probability which indicated positive and highly significant relationship. Age, farm size, farming experience, sociopolitical participation, efficiency of group leadership, group cohesiveness, decision making pattern and hard work orientedness were also positively and significantly correlated to perception at 5.00 per cent level of probability. Hence, null hypothesis was rejected and empirical hypothesis accepted for these variables. Therefore, it can be concluded that there is a positive and significant relationship between above profile characteristics and perception on the outcomes of implementation of IWMP.

On the other hand, the calculated ' $r$ ' values between perception and education, 
information seeking behaviour, annual income, type of irrigation, enterprise possessed and net returns were less than ' $r$ ' table value. Hence null hypothesis accepted and empirical hypothesis was rejected for these variables. Therefore, it can be concluded that there was no significant relationship between the profile characteristics and perception.

\section{Relationship between Profile characteristics and Extent of participation:}

The relationship between profile characteristics and extent of participation is briefly discussed below :

\section{Age and Extent of participation}

Age was found to be positively and significantly correlated with the extent of participation of watershed farmers in IWMP. The reason might be that majority of the respondents were of middle to old age group and the young farmers had not participated in watershed activities as compared to their counterparts.

\section{Education and Extent of participation}

From the findings it was revealed that most of the watershed farmers were educated up to primary level followed by illiterates and there was a positive and significant relationship between education and dependent variable participation. The reason might be that with the knowledge acquired as a result of education they could participated effectively. Therefore the management should initiate education efforts among the farmers for better participation in watershed as quite a good number of farmers belong to illiterate category.

\section{Farming experience and Extent of participation}

From the findings it is evident that majority of the watershed farmers had medium experience in farming which may be attributed to similar trends in the independent variable age where middle age respondents were more in number. Farming experience was found to be positively and significantly correlated with participation, as these is increase in experience the farmers tend to have more their interest in farming and thus participate more in watershed activities.

\section{Training received and Extent of participation}

Training received was found to have a significant and positive correlation with participation. Majority of the farmers had medium level of training received and it was observed that with increase in training, there was better participation. The IWMP gives importance to training on different stages and aspects of watershed which helps better participation. As there was good number of farmers with low training received, the management should look forward for more technical trainings to the farmers so that still better participation can be ensured and scientific based training on agricultural input and livestock management should be organized by efficient resource persons/ agencies.

\section{Socio-political participation and Extent of participation}

It was observed in the findings that socio-political participation had a positive and significant relationship with participation 
A study on extent of participation and perception of farmers on benefits of IWMP (Integrated Watershed Management Programme)

of the farmers in IWMP. With the trainings received, their participation increased and they played active role in village social organizations like youth clubs, water user association, user groups, SHGs and village watershed committees. The activities of these social organizations should be improved as it had a direct and positive relationship with participation of the farmers in IWMP. All the participating farmers should be given special priority in the Watershed management through SHGs approach. Similar findings were revealed by Sahoo and Dash (2013) and Puhan and Malla (2015).

\section{Efficiency of group leadership and Extent of participation}

From the findings it was revealed that the independent variable efficiency of group leadership was positively and significantly correlated with the dependent variable participation, which means better the efficiency of group leadership higher the participation of farmers in IWMP. The reason might be that with increased efficient leadership in the group, the participants could be motivated for more participation. The management should identify such efficient leaders from the community for better participation of the watershed farmers in IWMP.

\section{Group cohesiveness and Extent of participation}

From the findings it was evident that group cohesiveness was positively and significantly correlated with participation of watershed farmers in IWMP. The reason might be that mutual understanding, encouragement for group members, less conflicts disagreements the respondents feels better about the programme and participate more in IWMP activities. As the findings of the independent variable group cohesiveness shows medium to low trend the management should work towards better cohesiveness among the group members.

\section{Decision making pattern and Extent of participation}

The findings revealed that decision making pattern had a positive and significant relationship with participation. A democratic decision making pattern involving all stakeholders increases the trust among the participants which reflects in increased participation by the members. Therefore, the groups should be encouraged to take decisions after due consultation with all the members of the group.

\section{Hard work orientedness and Extent of participation}

From the findings it is evident that the independent variable hard work orientedness had positive and significant relationship with participation. The reason might be that with their experience in farming they might have found better results with hard work, which was reflected in the findings. The farmers who achieve due to their hard work should be projected in the community with rewards and recognitions, which may motivate other farmers.

\section{Perception on benefits of IWMP}

The results in Table 2 indicate that 
majority of the farmers had medium perception about all the three components viz. extent of usefulness (49.16\%), utilization (58.33\%) and satisfaction (55.00\%) on benefits of IWMP.

Table 3.

Distribution of Farmers according to their Perception on Benefits of IWMP

$n=120$

\begin{tabular}{|c|c|c|c|c|c|c|c|}
\hline \multirow[t]{2}{*}{ SI. No. } & \multirow[t]{2}{*}{ Category } & \multicolumn{2}{|c|}{$\begin{array}{l}\text { Extent of } \\
\text { usefulness }\end{array}$} & \multicolumn{2}{|c|}{$\begin{array}{l}\text { Extent of } \\
\text { utilization }\end{array}$} & \multicolumn{2}{|c|}{$\begin{array}{c}\text { Extent of } \\
\text { satisfaction }\end{array}$} \\
\hline & & $\mathbf{F}$ & $\%$ & $\mathbf{F}$ & $\%$ & $\mathbf{F}$ & $\%$ \\
\hline 1 & Low (43-72) & 23 & 19.16 & 16 & 13.33 & 12 & 10.00 \\
\hline 2 & Medium (72-101) & 59 & 49.16 & 70 & 58.33 & 66 & 55.00 \\
\hline 3 & High (101-130) & 38 & 31.66 & 34 & 28.33 & 42 & 35.00 \\
\hline
\end{tabular}

A statement containing 43 items describing recent watershed technologies was presented to the farmers and were requested to express their perception of these technologies in terms of extent of their usefulness, utilization and satisfaction. Based on the scores obtained on the rating scale, the data were classified under low, medium and high based on range of scores. It may be observed from the table that in terms of usefulness about half (49.16\%) of the respondents perceived it as medium while about one fourth (31.66\%) perceived it as high and the remaining (19.16\%) perceived it as low. We can conclude that the perception of respondents on extent of usefulness was medium to high. In terms of extent of utilization majority (58.33\%) perceived it as medium followed by high (28.33\%) and low (13.33\%) perception. This again led to the conclusion that the perception of respondents on extent of utilization was medium to high. In terms of extent of satisfaction, majority (55.00\%) had perceived it as medium followed by high
(35.00\%) and low (10.00\%) which followed the same trend of medium to high like the other two components. Thus the overall perception of the respondents on benefits of IWMP was medium to high which appears to be logical as all usefulness, utilization and satisfaction were interlinked.

\section{CONCLUSION}

The vision of the IWMP is to transform the elements of poverty into prosperity through effective watershed management programmes to sustain the rural livelihoods of the poor in drought prone areas. The mission of IWMP is to establish appropriate institutional structure for effective convergence in place and adopt holistic, integrated approach of managing various capitals, thus creating equal opportunities for communities through improved production systems as well as supportive employment generation. It is one of the tools, which can be utilized effectively for sustainable development of farmers, taking the results of the study in to consideration. 
A study on extent of participation and perception of farmers on benefits of IWMP (Integrated Watershed Management Programme)

\section{REFERENCES}

Bhattacharya, A. (2008). Sustainable livelihood based watershed management - Watershed plus approach. 1st Working Group Meeting of ERIA, Manila, Philippines.

Meshesha, Yericho, B., Birhanu \& Belay, S. (2015). Assessment of the effectiveness of watershed management intervention in Chena Woreda, Kaffa Zone, south western Ethiopia. Journal of Water Resource and Protection. 7(15): 1257-1269.

Puhan, R.R \& Malla, L. (2015). Impact and effectiveness of watershed development programmes in education and health in Keonjhar district of Odisha: A critical analysis. American Research Journal of Humanities and Social Sciences. 1(2): 6-16.

Sahoo, S \& Dash, A. (2013). Involvement of SHGs in watershed management - An impact analysis. Odisha Review. 49-52.

Saikat,M\&Surya, R. (2015). Social sustainability of natural resource management activities: A research in dry zone of West Bengal. Journal of Human Ecology. 50(2): 111-119.

Singh P, Behera, H.C \& Singh, A. (2010). Impact and effectiveness of watershed development programmes in India. Centre for Rural Studies. 29-54. 